www.jmscr.igmpublication.org

Index Copernicus Value: 79.54

ISSN (e)-2347-176x ISSN (p) 2455-0450

crossrefDOI: https://dx.doi.org/10.18535/jmscr/v7i3.139

\title{
Heart rate variability among Tobacco Chewers: A Case Control Study
}

\author{
Authors \\ Kumar Pradeep ${ }^{1}$, Shukla Jyotsna ${ }^{2^{*}}$, Saini Abhishek ${ }^{3}$, Patel Bhoopendra ${ }^{4}$ \\ ${ }^{1}$ Post Graduate Resident, ${ }^{2}$ Senior Professor, ${ }^{3}$ Assistant Professor, ${ }^{4}$ Senior Resident \\ Department of Physiology, SMS Medical College, Jaipur \\ *Corresponding Author \\ Jyotsna Shukla \\ Senior Professor, Department of Physiology, SMS medical College, Jaipur, India \\ Email: jyotsnashukla101@gmail.com
}

\begin{abstract}
Background: Tobacco chewing leads to dysfunction of autonomic nervous system has rarely been studied. Objective: Evaluation of heart rate variability $(H R V)$ in tobacco chewers for assessing autonomic functions.
\end{abstract}

Material and Methods: 30 male tobacco chewer subjects (age group 25-30 years) along with 30 aged and BMI matched male healthy controls were evaluated for Time domain parameters SDNN (ms); RMSSD (ms); pNN50 (\%) and Frequency domain HRV parameters: LF $\left(m s^{2}\right) ; H F\left(m s^{2}\right) ; \quad L F$ n.u. (\%); HF n.u. (\%) and LF/HF ratio. Level of significance derived using unpaired students " $t$ "-test.

Results: The mean HF n.u. (\%) was found to be lower whereas mean $L F\left(m s^{2}\right), L F$ n.u. (\%) and LF/HF ratio were found higher in tobacco chewers as compared to control group. ( $p$ value $<0.001$ )

Conclusion: Decreased Heart rate variability indicates deranged cardiovascular autonomic functions in tobacco chewer subjects.

Keywords: HRV, smokeless tobacco.

\section{Introduction}

Tobacco is the most widely distributed and commonly used habit forming substance for years. ${ }^{[1]}$

Many social factors, psychological states, economic and political factors have contributed to the global spread of tobacco consumption. ${ }^{[1]}$

An increase in consumption of smokeless tobacco has been noticed among high school, college students, and adults and indeed represents a health concern of growing magnitude among these groups. ${ }^{[2]}$
The prevalence of smokeless tobacco use is estimated at $29.6 \%$ for men and $12.8 \%$ for women and $21.4 \%$ of all adults in India as per Global Adult Tobacco Survey, India (2016-17). ${ }^{[3]}$

Smokeless tobacco contain more than 2500 chemicals including nicotine, carcinogenic chemicals such as tobacco-specific Nnitrosamines, benzopyrene, nitrate, cadmium, lead, arsenic, nickel, and chromium, flavoring additives and alkalines. ${ }^{\text {[2], [4], [5], [6] }}$

Smokeless tobacco chewing is associated with many health risks like oro-pharyngeal, esophageal 
and other cancers, cardiovascular diseases (MI,HTN, CVA etc), oral diseases (periodontitis, gingivitis) affecting all organ systems. ${ }^{[7],[8],[9]}$ Nicotine enhances the release of various neurotransmitters including epinephrine, norepinephrine, dopamine, acetylcholine, serotonin, vasopressin, glutamate, NO. ${ }^{[10]}$

Cardiovascular disease (CVD) is the leading cause of death worldwide, responsible for over 17 million annual deaths globally and tobacco has been estimated to directly cause $10 \%$ of all CVD worldwide and smokeless tobacco products contribute potential risk for cardiovascular mortality and morbidity. ${ }^{[11]}$

Analysis of heart rate variability (HRV) nowadays has become one of the most popular non-invasive tools for the detection of early autonomic nervous system dysfunction. Low variability in HR implies poor or inhibited ability to maintain internal homeostasis. Generally sympathetic influence increases HR (tachycardia response) and lowers variability of the heart rate, while parasympathetic input slows the HR (bradycardia response) and increases the variability. Low HRV is a known predictor of mortality in many clinical populations and it is associated with several cardiovascular risk factors. ${ }^{[12]}$ The present study is an attempt to an early understanding of the autonomic nervous system dysfunctions in tobacco chewer subjects using HRV to prevent cardiovascular morbidity and mortality in these subjects.

\section{Material and Methods}

The present study was conducted in the Department of Physiology, S.M.S. Medical College and Attached Hospitals, Jaipur, Rajasthan from $1^{\text {st }}$ March 2017 to $10^{\text {th }}$ January 2018 on 30 tobacco chewers between the age group of 25-30 years, taken from the various departments of S.M.S. Medical College and Attached hospitals, Jaipur along with 30 healthy age and sex matched non tobacco chewers, non smoker from the same departments of S.M.S. Medical college and attached Hospitals, Jaipur. It was a community based case-control type of observational study.
Prior permission was obtained from the institutional ethical committee and research review board.

Inclusion criteria for case group subjects: male tobacco chewers aged 25-30 years, chewing 5 gram or more tobacco/day. Exclusion criteria: any acute or chronic diseases like diabetes, liver diseases, cardiac diseases, smoking, alcoholism.

All subjects were tested between 10 am to 1.00 pm under similar laboratory conditions and were allowed to adapt themselves to experimental and environmental condition for 30 minutes to make them comfortable, as anxiety and stress can affect autonomic functions. The subjects were asked to avoid caffeine, carbonated drink, tobacco 12 hours prior to and after having light breakfast 2 hours' prior recording of $\mathrm{HRV}$. The room ambient temperature was maintained at $24-25^{\circ} \mathrm{C}$.

The recording of Heart Rate Variability was done by Polygraph (RMS Polyrite D, version 1.0) based on the principle of EKG.

For short term analysis of HRV, ECG was recorded in the supine posture for 5 minutes after 15 minutes of supine rest in a quiet environment.

Following parameters of HRV were included in Time \& Frequency Domain:

- $\operatorname{SDNN}(\mathrm{ms})$

- $\mathrm{RMSSD}(\mathrm{ms})$

- $\operatorname{pNN} 50(\%)$

- LF (Power in low frequency range) in $\mathrm{ms}^{2}$

- HF (Power in high frequency range) in $\mathrm{ms}^{2}$

- LF n.u. (normalized unit) in\%

- HF n.u. (normalised unit) in \%

- LF/HF ratio

Statistical analysis was performed using Microsoft Excel 2007 and unpaired students " $t$ "-test was used to derive the level of significance.

\section{Results}

The mean of time domain parameter SDNN (ms) for tobacco chewer subjects were $42.89 \pm 13.51$, while $43.23 \pm 11.37$ for control subjects. (p value $>0.05$ ) (Table 2) 
The mean of time domain parameter RMSSD (ms) for tobacco chewer subjects were 32.49 \pm 16.01 and $34.06 \pm 14.30$ for control subjects.

( $\mathrm{p}$ value $>0.05$ ) (Table 2 )

The mean of time domain parameter pNN50 (\%) were $12.73 \pm 14.69$ and $13.97 \pm 18.47$ for tobacco chewer and control subjects respectively.

In frequency domain parameter mean of $\mathrm{HF}\left(\mathrm{ms}^{2}\right)$ for tobacco chewers were $182.1 \pm 147.78$ and for control subjects 199.21 \pm 152.11 . (p-value $>0.05$ ) (Table 3)

The mean of frequency domain parameter HF n.u. for tobacco chewers were $33.21 \pm 10.25$ and for control subjects 57.44 \pm 8.44 . (p-value $<0.001)$ (Table 3)

The mean of frequency domain parameter LF $\left(\mathrm{ms}^{2}\right)$ for tobacco chewers were 399.47 \pm 342.59 and for control subjects $156.12 \pm 132.08$. (p-value $<0.05$ ) (Table 3)

The mean of frequency domain parameter LF n.u. for tobacco chewers were $66.76 \pm 10.61$ and for control subjects 42.45 \pm 8.47 . (p-value $<0.001$ ) (Table 3)

The mean of $\mathrm{LF} / \mathrm{HF}$ ratio for tobacco chewers and control subjects were $2.39 \pm 1.39$ and $0.76 \pm 0.21$ respectively. (p-value $<0.001$ ) (Table 3 )

Table: 1 Comparison of anthropometric and baseline clinical characteristics of tobacco chewer and control subjects:

\begin{tabular}{|c|c|c|c|c|}
\hline \multirow[t]{2}{*}{ Parameter } & \multicolumn{2}{|c|}{ Groups (Mean \pm SD) } & \multirow[t]{2}{*}{ p-value } & \multirow[t]{2}{*}{ Significance } \\
\hline & Case $(n=30)$ & Control $(\mathrm{n}=30)$ & & \\
\hline Age (years) & $27.83 \pm 1.64$ & $27.85 \pm 1.58$ & $>0.05$ & NS \\
\hline Weight $(\mathrm{kg})$ & $65.83 \pm 8.67$ & $66.5 \pm 7.92$ & $>0.05$ & NS \\
\hline Height $(\mathrm{cm})$ & $171 \pm 8.83$ & $174.03 \pm 6.56$ & $>0.05$ & NS \\
\hline BMI $\left(\mathrm{kg} / \mathrm{m}^{2}\right)$ & $21.78 \pm 2.09$ & $21.46 \pm 1.87$ & $>0.05$ & NS \\
\hline HR (beats/min) & $80.3 \pm 2.09$ & $74.10 \pm 6.23$ & $<0.05$ & Significant \\
\hline SBP (mmHg) & $123.2 \pm 9.30$ & $119.68 \pm 7.84$ & $>0.05$ & NS \\
\hline DBP (mmHg) & $77.67 \pm 7.70$ & $72.46 \pm 8.63$ & $<0.05$ & Significant \\
\hline
\end{tabular}

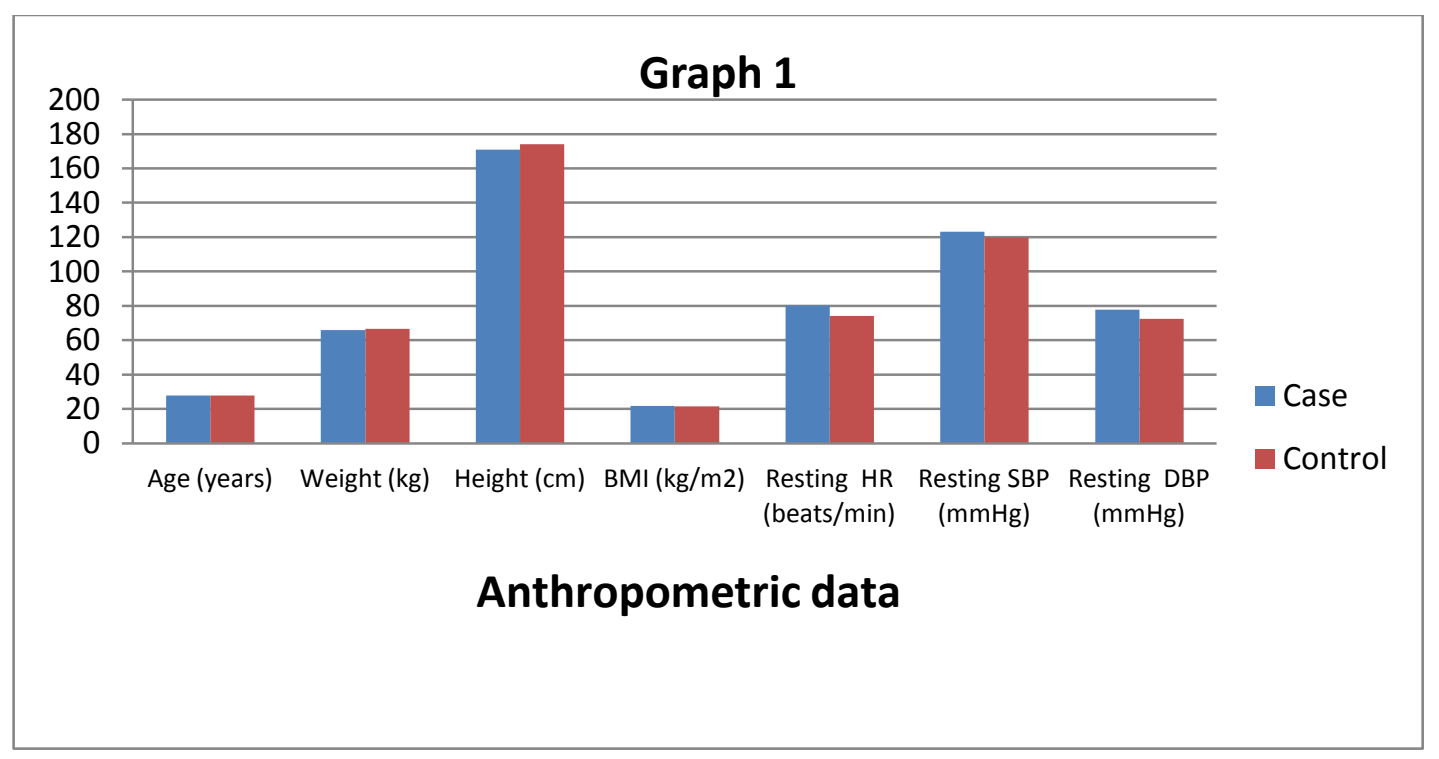

Table: 2 Comparison of Time domain HRV parameters in tobacco chewer and control subjects:

\begin{tabular}{|l|c|c|c|c|}
\hline \multirow{2}{*}{ Parameter } & \multicolumn{2}{|c|}{ Groups (Mean \pm SD) } & \multirow{2}{*}{-value } & Significance \\
\cline { 2 - 3 } & Case $(\mathrm{n}=30)$ & Control(n=30) & & \\
\hline SDNN $(\mathrm{ms})$ & $42.89 \pm 13.51$ & $43.23 \pm 11.37$ & $>0.05$ & NS \\
\hline RMSSD $(\mathrm{ms})$ & $32.49 \pm 16.01$ & $34.06 \pm 14.30$ & $>0.05$ & NS \\
\hline pNN 50 $(\%)$ & $12.73 \pm 14.69$ & $13.97 \pm 18.47$ & $>0.05$ & NS \\
\hline
\end{tabular}




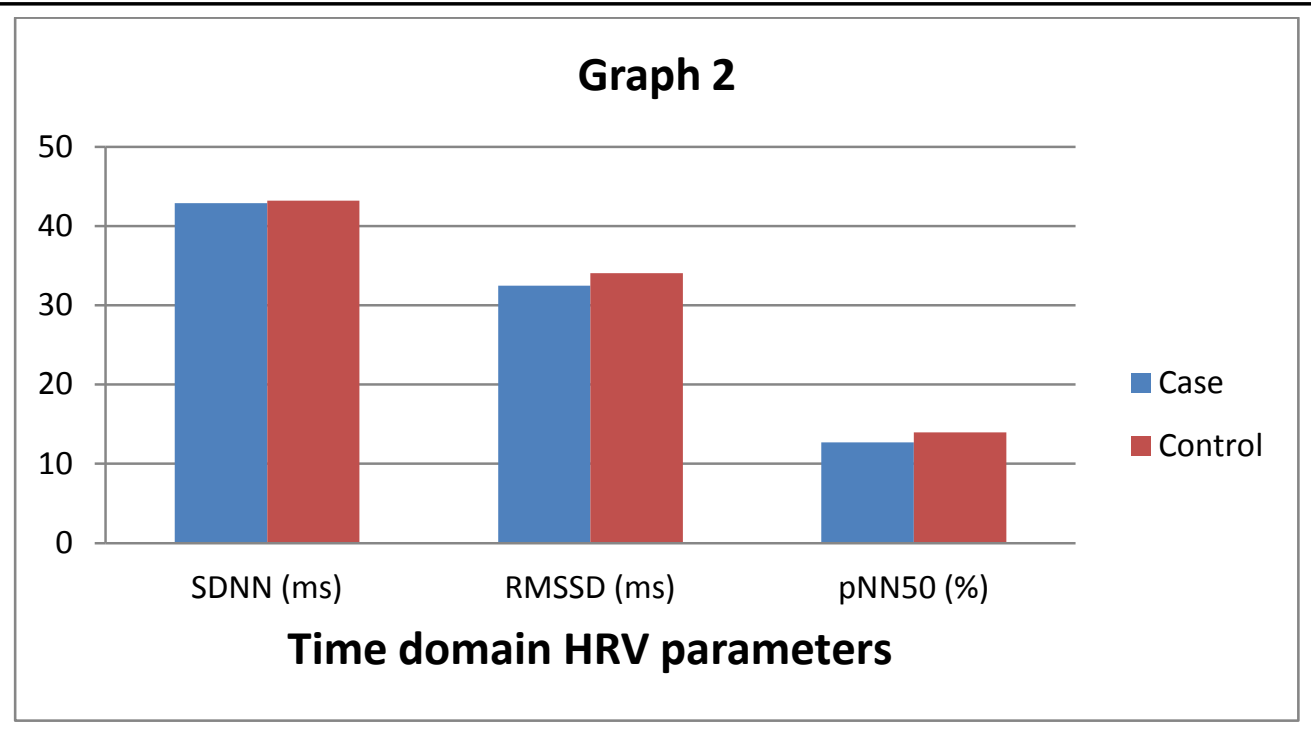

Table: 3 Comparison of frequency domain HRV parameters in tobacco chewer and non tobacco chewer subjects:

\begin{tabular}{|l|c|c|c|c|}
\hline \multirow{2}{*}{ Parameter } & \multicolumn{2}{|c|}{ Groups (Mean \pm SD) } & \multirow{2}{*}{-value } & Significance \\
\cline { 2 - 3 } & Case $(\mathrm{n}=30)$ & Control $(\mathrm{n}=30)$ & & \\
\hline $\mathrm{HF}\left(\mathrm{ms}^{2}\right)$ & $182.1 \pm 147.78$ & $199.21 \pm 152.11$ & $>0.05$ & NS \\
\hline LF $\left(\mathrm{ms}^{2}\right)$ & $399.47 \pm 342.59$ & $156.12 \pm 132.08$ & $<0.05$ & HS \\
\hline HF n.u. & $33.21 \pm 10.25$ & $57.44 \pm 8.44$ & $<0.001$ & HS \\
\hline LF n.u. & $66.76 \pm 10.61$ & $42.45 \pm 8.47$ & $<0.001$ & HS \\
\hline LF/HF ratio & $2.39 \pm 1.39$ & $0.76 \pm 0.21$ & $<0.001$ & HS \\
\hline
\end{tabular}

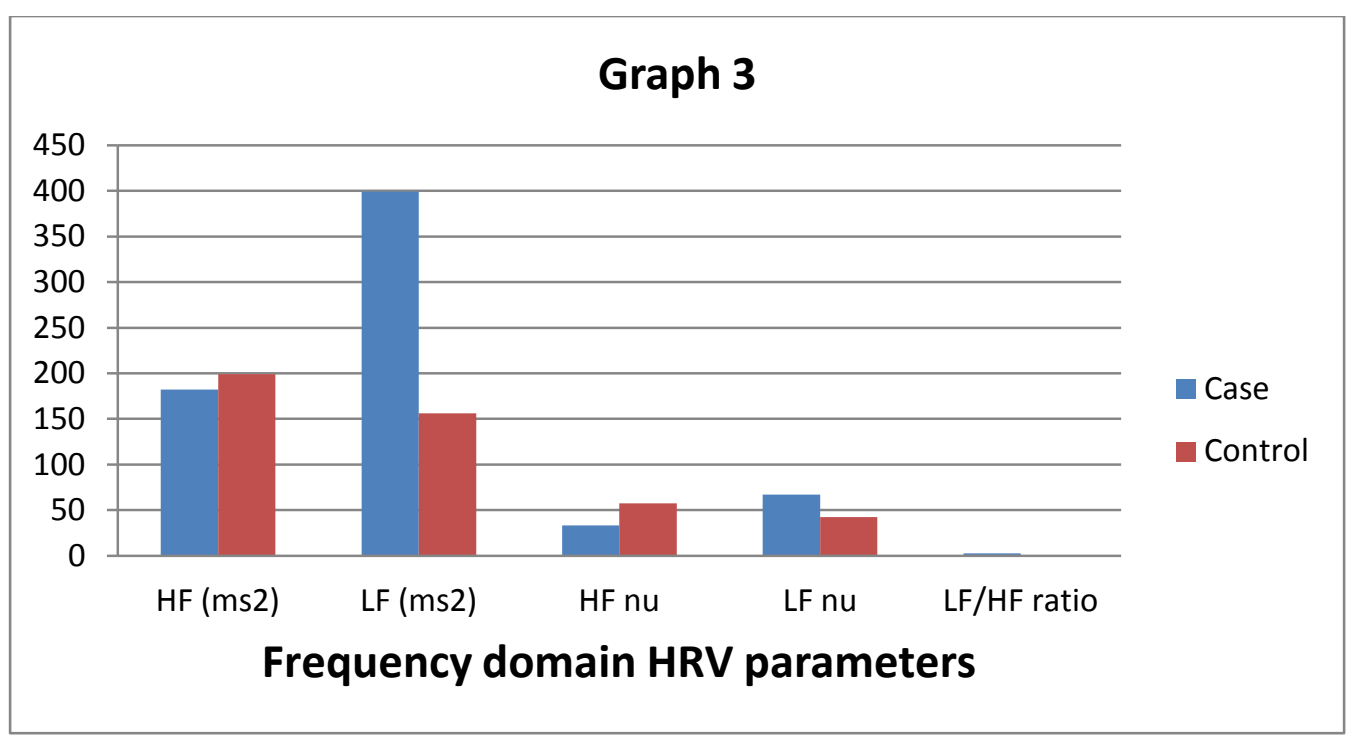

\section{Discussion}

In recent years, there has been increasing trend of tobacco chewing in youngsters ${ }^{[2]}$.

Consumption of tobacco in any form has harmful effects on health, which leads to disease, disability and death.

Apart from serious ill effects on various systems of body, chewing tobacco is one of the important causes of cardiovascular morbidity and mortality. [11], [17]

Cardiovascular system is influenced by autonomic nervous system and use of smokeless tobacco leads to sympatho-vagal imbalance, which may leads to MI, HTN, stroke and arrhythmia etc in future. ${ }^{[18]}$ 
Despite extensive health burden of tobacco chewing, only a small number of studies have explored its effect on cardiovascular health.

HRV is a simple, economic, non invasive technique to evaluate sympatho-vagal balance and widely used method to assess autonomic functional status. ${ }^{[12]}$

\section{Time domain parameters of HRV}

Mean value of SDNN, RMSSD and pNN50 mean values were $42.89 \pm 13.51, \quad 32.49 \pm 16.01$ and $12.73 \pm 14.69$ in tobacco chewers respectively and $43.23 \pm 11.37,34.06 \pm 14.30$ and $13.97 \pm 18.47$ in control subjects respectively. Although the values are higher in controls as compared to tobacco chewers, the difference is statistically not significant. $(\mathrm{p}>0.05)$

Our observations supported by the studies of Mohesh MIG et al ${ }^{[14]}$ and Pakkala A et al. ${ }^{[13]}$ was found to be higher

\section{Frequency domain parameters of $\mathrm{HRV}$}

Mean of LF absolute power was found to be $399.47 \pm 342.78 \mathrm{~ms}^{2}$ in tobacco chewers as compared from $156.12 \pm 132.08 \mathrm{~ms}^{2}$ in control subjects $(\mathrm{p}<0.05)$ and mean of LF n.u. was found to be $66.76 \pm 10.61$ in tobacco chewers as compared from $42.45 \pm 8.47$ in control subjects $(\mathrm{p}<0.001)$.

These findings emphasized sympathetic over activity in tobacco chewers. These results were comparable with Pakkala A et al ${ }^{[13]}$, Doss DSD et al. ${ }^{[16]}$

Mean of HF n.u.(\%) in tobacco chewers was significantly lower $(33.21 \pm 10.25)$ as compared to control subjects $(57.44 \pm 8.44), \quad(p<0.001)$ and $\mathrm{LF} / \mathrm{HF}$ ratio was found to be significantly higher in tobacco chewers $(2.39 \pm 1.39)$ as compared to in control subjects $(0.76 \pm 0.21),(\mathrm{p}<0.001)$. Studies of Pakkala A et al ${ }^{[13]}$ and Doss DSD et al ${ }^{[16]}$ corroborate our findings.

The pathophysiological footing of the development of autonomic dysfunctions in tobacco chewers is not clearly known, however literature suggests that nicotine and additives present in tobacco release epinephrine from adrenal gland in response to using tobacco \& increase in plasma epinephrine causes preganglionic sympathetic excitation. It can lead to dominance of sympathetic nervous system over the parasympathetic nervous activity in tobacco chewers. ${ }^{[10]}$

Our study results showed hyperactive sympathetic and hypoactive parasympathetic system in tobacco chewers as compared to non tobacco chewers.

\section{Conclusion}

Chewing tobacco in any form predisposes for autonomic dysfunctions, which may lead to cardiovascular morbidity and mortality. Therefore HRV testing can be used to screen the subjects consuming tobacco for timely diagnosis and treatment to limit further complications.

\section{Limitation}

Study was conducted on small sample size in short time duration. For better results large sample size spanned over a longer time duration may be taken.

\section{References}

1. Soni P, Raut DK. Prevalence and Pattern of Tobacco Consumption in India. International Research Journal of Social Sciences. 2012; 1(4): 36-43.

2. Itagi $\mathrm{ABH}$, Arora $\mathrm{D}$, Patil NA, Bailwad SA, Yunus GY, Goel A. Short-term acute effects of gutkha chewing on heart rate variability among young adults._Int J Appl Basic Med Res. 2016; 6(1): 45-49.

3. Fact Sheet.GATS-2: Global Adult Tobacco Survey. India 2016-17.

4. Sharma P, Murthy P, Shivhare P. Nicotine quantity and packaging disclosure in smoked and smokeless tobacco products in India. Indian j Pharmacol. 2015; 47(4): 440-443.

5. Djordjevic MV, Doran KA, Nicotine content and delivery across tobacco 
products. Handb Exp Pharmacol. 2009;192:61-82.

6. Chiou SS,Kuo CD. Effect of chewing a single betel-quid on autonomic nervous modulation in healthy young adults. Journal of Psychopharmacology. 2008;22(8) : 910-917.

7. Omole OB, Ogunbanjo GA. Smokeless tobacco: is it really safe?. South African Family Practice, 2009;51(4): 292-295.

8. Gupta PC, Ray CS. Smokeless tobacco and health in India and South Asia. Respirology 2003, 8(4):419-431.

9. Baljoshi, Begum N, Sandhya HP, Tejaswini, Kulkarni SB. Effect of tobacco Chewing on cardiovascular autonomic function tests. International Physiology. 2013;1(1).

10. Puri A, Chaudhary G, Srivastava R, Tiwari S. Electrical Disturbance in Heart by Smokeless Tobacco. Journal of the association of physicians of india.May 2013 ; VOL. 61.

11. Piano MR, Benowitz NL, FitzGerald GA, Corbridge S, Heath J,Hahn E et al. Impact of Smokeless Tobacco Products on Cardiovascular Disease: Implications for Policy, Prevention, and Treatment. American Heart Association, Inc. 2010;122:1520-1544.

12. Task Force of the European Society of Cardiology and the North American Society of Pacing and Electrophysiology. Heart rate variability, standards of measurement, physiological interpretation, and clinical use. Circulation 1996; 93:1043-1065.

13. Pakkala A et al. A Study of Heart Rate Variability among Gutkha Chewers from a Rural Farming Background in India. J Alcoholism Drug Depend 2013;1:115
14. Mohesh MIG et al. A study of short term heart rate variability in dipping tobacco users. Asian Journal of Medical Sciences. Jul-Sep 2014 ; 5(3).

15. Gondim RM, Farah BQ, Santos CF, RittiDias RM. Are smoking and passive smoking related with heart rate variability in male adolescents?. Einstein. 2014.

16. Doss DSD, Anandhalakshmi S, Rekha K, Akhil AK. Effect of smoking on heart rate variability in normal healthy volunteers. Asian Journal of Pharmaceutical and Clinical Research. 2016;9(4):230-234.

17. Gupta BK, Kaushik A, Panwar RB, Chaddha VS, Nayak KC, Singh VB et al. Cardiovascular risk factors in tobaccochewers: A controlled study. J Assoc Physicians India. 2007;55:27-31.

18. Critchley JA, Unal B. Mortality risk reduction associated with smoking cessation in patients with coronary heart disease: A systematic review JAMA.2003;290:86-97. 